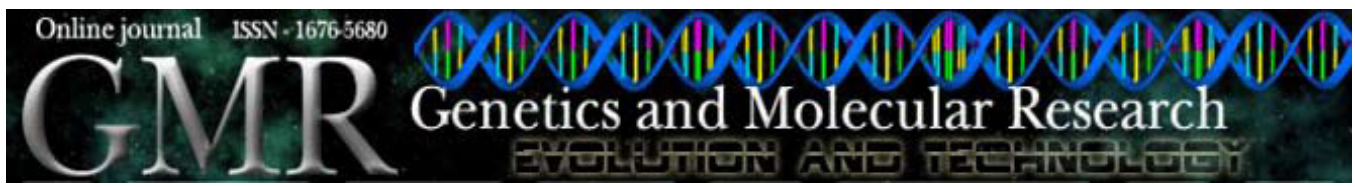

\title{
Phylogenetic relationships of leaf monkeys (Presbytis; Colobinae) based on cytochrome $b$ and 12S rRNA genes
}

\author{
V.F. Vun', M.C. Mahani', M. Lakim², A. Ampeng' ${ }^{1,3}$ and B.M. Md-Zain ${ }^{1}$ \\ ${ }^{1}$ School of Environmental and Natural Resource Sciences, \\ Faculty of Science and Technology, Universiti Kebangsaan Malaysia, \\ Bangi, Selangor, Malaysia \\ ${ }^{2}$ The Broad of Trustee of Sabah Parks, Sabah, Malaysia \\ ${ }^{3}$ Sarawak Forestry Department, Kuching, Sarawak, Malaysia \\ Corresponding author: B.M. Md-Zain \\ E-mail: abgbadd@ukm.my/abgbadd1966@yahoo.com
}

Genet. Mol. Res. 10 (1): 368-381 (2011)

Received September 1, 2010

Accepted December 10, 2010

Published March 1, 2011

DOI 10.4238/vol10-1gmr1048

\begin{abstract}
Little is known about the classification and phylogenetic relationships of the leaf monkeys (Presbytis). We analyzed mitochondrial DNA sequences of cytochrome $b$ (Cyt $b$ ) and 12S rRNA to determine the phylogenetic relationships of the genus Presbytis. Gene fragments of 388 and 371 bp of Cyt $b$ and $12 \mathrm{~S}$ rRNA, respectively, were sequenced from samples of Presbytis melalophos (subspecies femoralis, siamensis, robinsoni, and chrysomelas), P. rubicunda and $P$. hosei. The genus Trachypithecus (Cercopithecidae) was used as an outgroup. The Cyt $b \mathrm{NJ}$ and MP phylogeny trees showed $P$. m. chrysomelas to be the most primitive, followed by $P$. hosei, whereas $12 \mathrm{~S}$ rRNA tree topology only indicated that these two species have close relationships with the other members of the genus. In our analysis, chrysomelas, previously classified as a subspecies of $P$. melalophos, was not included in either the P. m. femoralis clade or the P. m. siamensis clade. Whether or not there should be a separation at the species level remains to be clarified. The tree topologies also showed that $P$. m. siamensis is paraphyletic with $P$. $m$. robinsoni, and $P$. m. femoralis with P. rubicunda, in two different
\end{abstract}


clades. Cyt $b$ and 12S rRNA are good gene candidates for the study of phylogenetic relationships at the species level. However, the systematic relationships of some subspecies in this genus remain unclear.

Key words: Presbytis; Cytochrome $b$ gene; 12S rRNA gene; Colobinae; Leaf monkeys

\section{INTRODUCTION}

Presbytis, the genus of the leaf monkey, subfamily Colobinae, superfamily Cercopithecidae, is the Asian langur confined to the Sundaland (Figure 1) such as the Malay Peninsula, Thailand, Indonesia (Sumatra, Java, Natuna Island, Riau Island, and Mentawai Island) and Borneo (Oates et al., 1994; Meijaard and Groves, 2004; Ampeng and Md-Zain, 2007). Generally, the number of species in Presbytis range from four to eleven, depending on the researcher (Md-Zain, 2001). Our research, however, closely follows the classification of Oates et al. (1994) and MdZain et al. (2008), who classified Presbytis into seven species, namely P. melalophos, P. rubicunda, P. frontata, P. potenziani, P. thomasi, P. hosei, and P. comata. To date, most of the phylogenetic relationships of the proposed Presbytis species were based on morphological traits such as coat coloration, head pattern, vocals of the adult male, behavioral studies such as social structure of the group, and ecological studies (Napier, 1985; Peng et al., 1993; Oates et al., 1994). Brandon-Jones (1996a), using coat coloration, suggested that the most primitive form of Presbytis is $P$. potenziani found on Mentawai Island, Indonesia, followed by the intermediate forms ( $P$. comata, $P$. thomasi and $P$. hosei) and the derived forms (P. melalophos, $P$. femoralis, $P$. frontata, and $P$. rubicunda). According to him, the most primitive form has a dark coloration, intermediate with grey coloration, and the derived forms have the greatest color variation, ranging from red to brown. For the derived forms, a special affinity between the P. melalophos and P. rubicunda was proposed by Brandon-Jones (1996b) in view of their behavioral similarity. The evolutionary relationships of the derived forms also showed that $P$. rubicunda was a derivation of $P$. siamensis (based on head pattern). Based on the shared external cephalic structure of $P$. frontata and $P$. comata sabana, these two species were also thought to have a close relationship (Brandon-Jones, 1996b).

Medway (1970), on the other hand, taking into consideration the entry point of Presbytis, which is from mainland Asia, discovered that the Mentawai Island fauna had similar characteristics as those of Sumatra from which it was derived. Thus, it was proposed that the P. potenziani was the descendent of the first primate that inhabited Sumatra. The Sumatran primate later separated and underwent speciation due to geographical movement. Md-Zain (2001) and Md-Zain et al. (2008), adopting various molecular techniques, including maternal (mitochondrial ND3, ND4L, ND4 and tRNAs), paternal (TSPY and SRY) and biparental autosomal (IRBP intron 3) markers in their study on several Presbytis species found that the $P$. comata, P. thomasi and $P$. hosei are respectively independent, and that $P$. rubicunda and $P$. melalophos are not closely related, with the $P$. rubicunda grouped into a clade containing $P$. comata and $P$. thomasi. Therefore, it was concluded that $P$. rubicunda has a close relationship with $P$. comata and $P$. thomasi. Contrary to the theoretical ancestry put forward by Brandon-Jones, the Borneo Presbytis also underwent cladogenic splits that separated the P. hosei from all other Presbytis, and the latter underwent a further division into the melalophos group and comata-thomasi-rubicunda group (Md-Zain, 2001; Meijaard and Groves, 2004). 


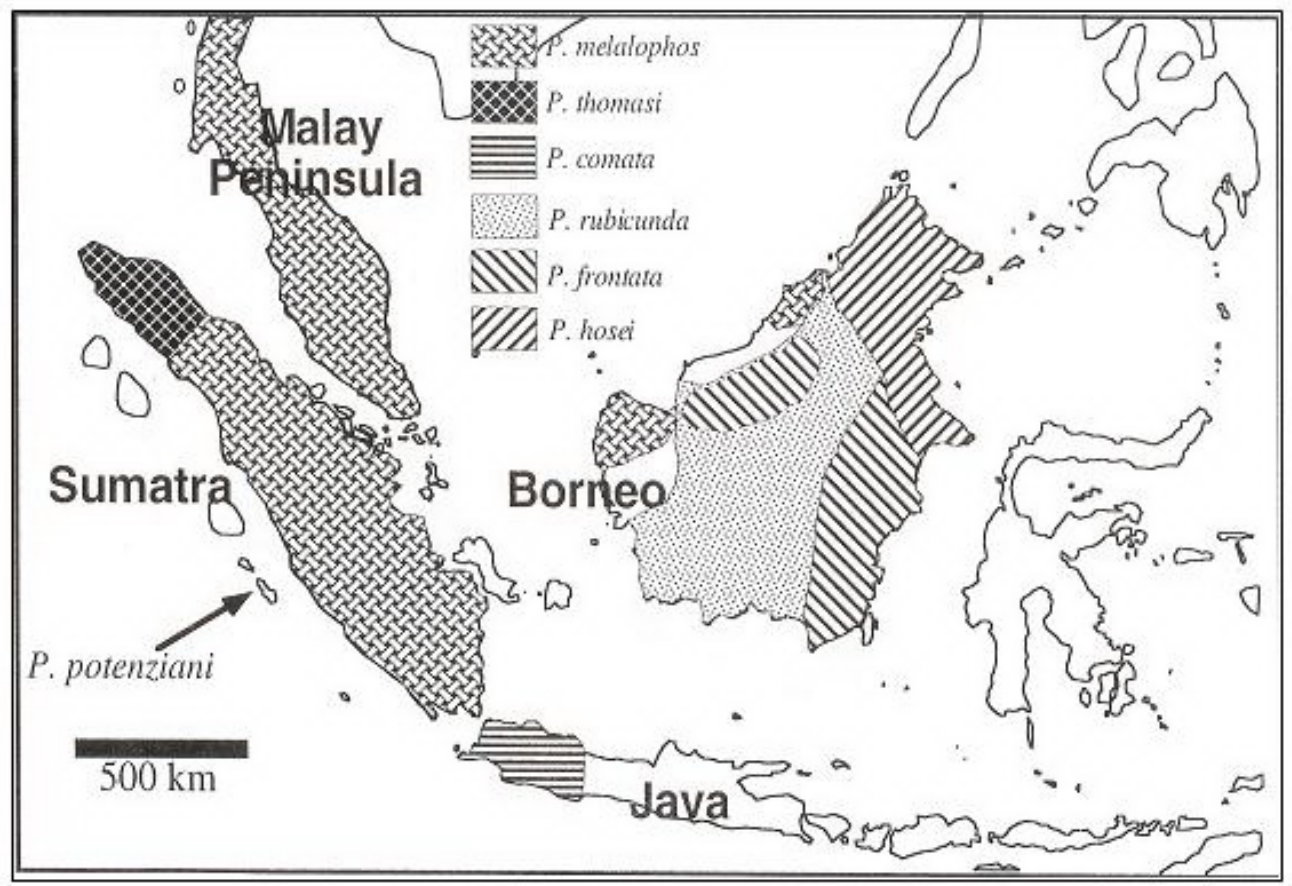

Figure 1. The geographical distribution of the seven Presbytis species according to Oates et al. (1994) and adapted from Md-Zain et al. (2008).

Mitochondrial DNA (mtDNA) has been widely used to infer phylogenetic relationships of closely related species of both vertebrates and invertebrates due to its unique characteristics. It has a high evolutionary rate as compared to the nuclear genome, and is maternally inherited, resulting in the lack or absence of DNA recombination, coupled with its relatively small size that give it an advantage for manipulation in the laboratory (Melnick and Hoelzer, 1993). Consequently, a large comparative database of mitochondrial sequences is easily available and accessible nowadays (Shahrom et al., 2005; Sterner et al., 2006; Karanth, 2008; Khan et al., 2008; Lim et al., 2010; Md-Zain et al., 2010a,b). In the present study, mtDNA cytochrome $b$ (Cyt $b$ ) and 12S rRNA were sequenced and analyzed to obtain a full understanding as well as to clarify the controversies associated with Presbytis classification and phylogeny.

\section{MATERIAL AND METHODS}

\section{Samples}

Thirty-seven genetic samples of P. melalophos (subspecies femoralis, siamensis, robinsoni, and chrysomelas), P. rubicunda, P. hosei, and the outgroup (Trachypithecus obscurus, T. cristatus, and T. auratus) were used (Table 1). 
Table 1. Samples of species used in this study.

\begin{tabular}{|c|c|c|}
\hline Sample code & Species & Location \\
\hline PmsBM 21 & P. m. siamensis & Ulu Besut, Terengganu, Malaysia \\
\hline PmsBM 22 & P. m. siamensis & Ulu Besut, Terengganu, Malaysia \\
\hline PmsBM 23 & P. m. siamensis & Ulu Besut, Terengganu, Malaysia \\
\hline PmsBM 24 & P. m. siamensis & Ulu Besut, Terengganu, Malaysia \\
\hline PmsBM 25 & P. m. siamensis & Kuala Krai, Kelantan, Malaysia \\
\hline PmsBM 26 & P. m. siamensis & Kuala Krai, Kelantan, Malaysia \\
\hline PmrBM 27 & P. m. robinsoni & Kuala Kangsar, Perak, Malaysia \\
\hline PmrBM 28 & P. m. robinsoni & Kuala Kangsar, Perak, Malaysia \\
\hline PmrBM 31 & P. m. robinsoni & Kuala Kangsar, Perak, Malaysia \\
\hline PmrBM 30 & P. $m$. robinsoni & Selama, Perak, Malaysia \\
\hline PmrBM 33 & P. $m$. robinsoni & Selama, Perak, Malaysia \\
\hline PmfBM 35 & P. m. femoralis & Kluang, Johor, Malaysia \\
\hline PmfBM 36 & P. m. femoralis & Kluang, Johor, Malaysia \\
\hline PmfBM 37 & P. m. femoralis & Kluang, Johor, Malaysia \\
\hline PmfBM 38 & P. m. femoralis & Kluang, Johor, Malaysia \\
\hline PmfBM 39 & P. m. femoralis & Mersing, Johor, Malaysia \\
\hline PmfBM 40 & P. m. femoralis & Mersing, Johor, Malaysia \\
\hline PmfBM 41 & P. m. femoralis & Mersing, Johor, Malaysia \\
\hline PmfBM 42 & P. m. femoralis & Mersing, Johor, Malaysia \\
\hline PmfBM 43 & P. m. femoralis & Kota Tinggi, Johor, Malaysia \\
\hline PmfBM 45 & P. m. femoralis & Kota Tinggi, Johor, Malaysia \\
\hline PmfBM 46 & P. m. femoralis & Kota Tinggi, Johor, Malaysia \\
\hline PmfBM 47 & P. m. femoralis & Pontian, Johor, Malaysia \\
\hline PmcrAA 04 & P. m. chrysomelas & Tanjong Datu, Sarawak, Malaysia \\
\hline PmcrAA 05 & P. m. chrysomelas & Tanjong Datu, Sarawak, Malaysia \\
\hline PrBM 101 & P. rubicunda & Tawau, Sabah, Malaysia \\
\hline PrMK 01 & P. rubicunda & Tawau, Sabah, Malaysia \\
\hline PhBM 67 & P. hosei & Tawau, Sabah, Malaysia \\
\hline $\mathrm{PhBM} 70$ & P. hosei & Danum Valley, Sabah, Malaysia \\
\hline TcAA 01 & T. cristatus & Tanjong Datu, Sarawak, Malaysia \\
\hline TcBM 01 & T. cristatus & Kota Kuala Muda, Kedah, Malaysia \\
\hline TcBM 02 & T. cristatus & Kota Kuala Muda, Kedah, Malaysia \\
\hline ТaВM 99 & T. auratus & East Java \\
\hline ToBM 07 & T. obscurus & Sik, Kedah, Malaysia \\
\hline ToBM 09 & T. obscurus & Changloon, Kedah, Malaysia \\
\hline ToBM 15 & T. obscurus & Suluk Paya Dalam, Melaka, Malaysia \\
\hline ToBM 17 & T. obscurus & Suluk Paya Dalam, Melaka, Malaysia \\
\hline
\end{tabular}

\section{DNA extraction and PCR amplification}

Genomic DNA from the muscles was extracted using the GeneAll ${ }^{\mathrm{TM}}$ kit (General Biosystem (GBS), Inc., Korea). Primer pairs of L14724 and H15149 (Pääbo and Wilson, 1988; Kocher et al., 1989) and L1091 and H1478 (Kocher et al., 1989) were used to amplify the Cyt $b$ and 12S rRNA partial gene sequences, respectively. Polymerase chain reaction (PCR) amplification was performed in the GeneAmp PCR system 2400 (Perkin Elmer) and PTC-100 ${ }^{\mathrm{TM}}$ Programmable Thermal Controller (MJ Research Inc., USA) in a 50- $\mu \mathrm{L}$ reaction volume containing $10 \mathrm{X}$ buffer, $1 \mu \mathrm{L} 10 \mathrm{mM}$ dNTPs, $1 \mu \mathrm{L}(10 \mathrm{pmol})$ of each primer, $2.5 \mathrm{U} / \mu \mathrm{L}$ Taq polymerase (Invitrogen) and $\mathrm{ddH}_{2} \mathrm{O}$. Double-stranded PCR amplifications were performed using the following conditions: $30-35$ cycles of denaturation at $94^{\circ} \mathrm{C}$, annealing at $55^{\circ} \mathrm{C}$ for Cyt $b$ and $53.6^{\circ} \mathrm{C}$ for $12 \mathrm{~S} \mathrm{rRNA}$, and extension at $72^{\circ} \mathrm{C}$, with final extension at $72^{\circ} \mathrm{C}$ for $10 \mathrm{~min}$. Cycles of denaturation, annealing and extension were performed for $1 \mathrm{~min}$, respectively. The PCR product was purified using QIAquick PCR Purification and Gel Purification kit (QIAGEN Inc., USA) and sequenced for both strands by First Base Laboratories, Sdn Bhd, Malaysia. 


\section{Alignments and phylogenetic analyses}

The alignment of the sequences were performed via ClustalX (Thompson et al., 1997) and the resulting alignment was adjusted visually. Prior to the multiple alignment, the sequences were manually edited by visual analysis and then using computer software, Chromas (Technelysium Pty., Ltd.) and/or BioEdit version 7.0.2. The genetic distance was tabulated using the Kimura-2-parameter method (Kimura, 1980) in PAUP 4.0b10 (Swofford, 2002). Phylogenetic reconstructions were obtained via the neighbor joining (NJ) and maximum parsimony (MP) methods in PAUP 4.0b10 packages (Swofford, 2002). Heuristic search with the stepwise addition method was performed for 1000 replicates in MP analysis for Cyt $b$ and $12 \mathrm{~S}$ rRNA data for all the samples. The confidence of the NJ and MP tree was assessed via bootstrap resampling (based on 1000 resampling events) to estimate the stability of the tree topologies. A strict consensus tree was constructed for all arrangements. The transition and transversion ratio and the position of these substitutions were analyzed by MEGA version 3.1 (Kumar et al., 2004). An outgroup of Trachypithecus species was used to root the phylogenetic tree in this study.

\section{RESULTS}

Amplification products of 388 and 371 bp were obtained for Cyt $b$ and 12S rRNA gene fragments, respectively. Sequence analysis indicated that of the 156 variable sites within the Cyt $b$ gene, 124 were parsimony informative. Meanwhile, among 54 variable sites within $12 \mathrm{~S}$ rRNA, 49 were found to be parsimony informative. The nucleotide substitutions for the Cyt $b$ and 12S rRNA revealed that both genes were rich in transition, with 38 transitions among 44 substitutions for Cyt $b$ and 14 transitions among a total of 22 substitutions in $12 \mathrm{~S}$ rRNA sequences. The Ti/Tv ratio for Cyt $b$ was 9.3 after excluding the outgroups. The Ti/Tv ratio of $12 \mathrm{~S}$ rRNA, however, was significantly lower than for Cyt $b$, which was 1.6 after the exclusion of the outgroups. An MP tree with tree length of $236(\mathrm{CI}=0.6398, \mathrm{HI}=0.3602, \mathrm{RI}=0.9101)$ was chosen as the best tree for Cyt $b$, whereas for $12 \mathrm{~S}$ rRNA, the best MP tree length was $79(\mathrm{CI}=0.7848, \mathrm{HI}=0.2152, \mathrm{RI}=$ $0.9433)$.

Analysis of the pairwise sequences using the Kimura-2-parameter of Cyt $b$ for each individual in Presbytis showed a low distance value (0.159), indicating that these individuals were closely related to each other. The average sequence divergence within all $P$. m. femoralis was 0.00590 , within $P$. $m$. siamensis 0.02776 , within $P$. m. robinsoni 0.04139 , within $P$. m. chrysomelas 0.00258 , within $P$. hosei 0.01826 , and within $P$. rubicunda 0.00258 (Table 2). The average genetic distance of individuals within a species was relatively very low, that is, $<4.1 \%$. At the interspecies level, the average pairwise genetic distances revealed relatively distant relationships among the species except for $P$. $m$. siamensis and $P$. m. robinsoni. Analysis of the distance matrices generated by $12 \mathrm{~S}$ rRNA also showed an average distance divergence at the intraspecies level that was relatively lower, which is less than $1.6 \%$. $12 \mathrm{~S}$ rRNA also gave relatively low average sequence divergence as compared to the average sequence divergence of Cyt $b$ at the interspecies level (Table $3)$. Therefore, the results indicated that all the individuals in this genus have very close relationships. 
Table 2. Average pairwise genetic distances for Cyt $b$ gene between species and subspecies of Presbytis.

\begin{tabular}{|c|c|c|c|c|c|c|}
\hline & femoralis & siamensis & robinsoni & chrysomelas & hosei & rubicunda \\
\hline femoralis & 0.006 & & & & & \\
\hline siamensis & 0.111 & 0.028 & & & & \\
\hline robinsoni & 0.100 & 0.058 & 0.041 & & & \\
\hline chrysomelas & 0.124 & 0.133 & 0.122 & 0.003 & & \\
\hline hosei & 0.126 & 0.147 & 0.135 & 0.131 & 0.018 & \\
\hline rubicunda & 0.095 & 0.134 & 0.128 & 0.114 & 0.146 & 0.003 \\
\hline
\end{tabular}

Table 3. Average pairwise genetic distances for 12S rRNA gene between species and subspecies of Presbytis.

\begin{tabular}{lcccccc}
\hline & femoralis & siamensis & robinsoni & chrysomelas & hosei & rubicunda \\
\hline femoralis & 0.002 & & & & & \\
siamensis & 0.050 & 0.011 & & & \\
robinsoni & 0.049 & 0.025 & 0.016 & 0.003 & 0.003 & 0.036 \\
chrysomelas & 0.042 & 0.052 & 0.053 & 0.034 & 0.051 & 0.000 \\
hosei & 0.037 & 0.051 & 0.054 & & & \\
rubicunda & 0.030 & 0.056 & & &
\end{tabular}

The phylogenetic relationships among the species and subspecies of Presbytis are shown in the NJ trees for Cyt $b$ (Figure 2) and 12S rRNA (Figure 3). The MP trees obtained for both Cyt $b$ and 12S rRNA (Figures 4 and 5) were very similar to the NJ trees obtained. The Cyt $b$ phylogram (Figures 2 and 4) showed that the three species endemic to Peninsular Malaysia (P. m. femoralis, P. m. siamensis and P. m. robinsoni) diverged from the Borneo P. hosei. The peninsular species were further separated into two clades, with one clade including the individuals of $P$. $m$. robinsoni and $P$. m. siamensis (clade I) and the second consisting of $P . m$. femoralis. Our analyses showed that $P$. m. robinsoni diverged earlier than $P$. $m$. siamensis and that there is an ongoing evolutionary process currently between these two subspecies with the presence of individuals with intermediate characters (PmrBM33, PmrBM30, PmsBM26, and PmsBM25), which showed very high NJ and MP bootstrap values of 98 and 94, respectively. These individuals were found to share 10 intermediate nucleotide characters between the species with four unique nucleotide characters, which were only found in PmrBM33, PmrBM30, PmsBM26, and PmsBM25 individuals. In addition to the 10 intermediate and four unique characters, the two subspecies generally clustered together based on 13 other characters, which were only found within these two subspecies. Similary, the 12s RNA NJ and MP trees also showed a grouping of robinsoni and siamensis in a single clade (Figures 3 and 5, Clade I). Our analysis of the $12 \mathrm{~S}$ rRNA nucleotide sequences of robinsoni-siamensis revealed that these two species were clustered together based on five unique nucleotides only present in these species and a shared intermediate character. In alignment with the Cyt $b$ tree topologies, the 12S rRNA tree topologies also showed an ongoing evolutionary process between the robinsoni and siamensis with the presence of the same four individuals (PmrBM33, PmrBM30, PmsBM26, and PmsBM25) sharing three unique nucleotide characters just amongst them. The bootstrap values obtained for the intermediate individuals were 85 for NJ and 82 for MP. High NJ and MP bootstrap values obtained for both Cyt $b$ and 12S rRNA showed that the ongoing evolution of robinsoni-siamensis was quite consistent. 


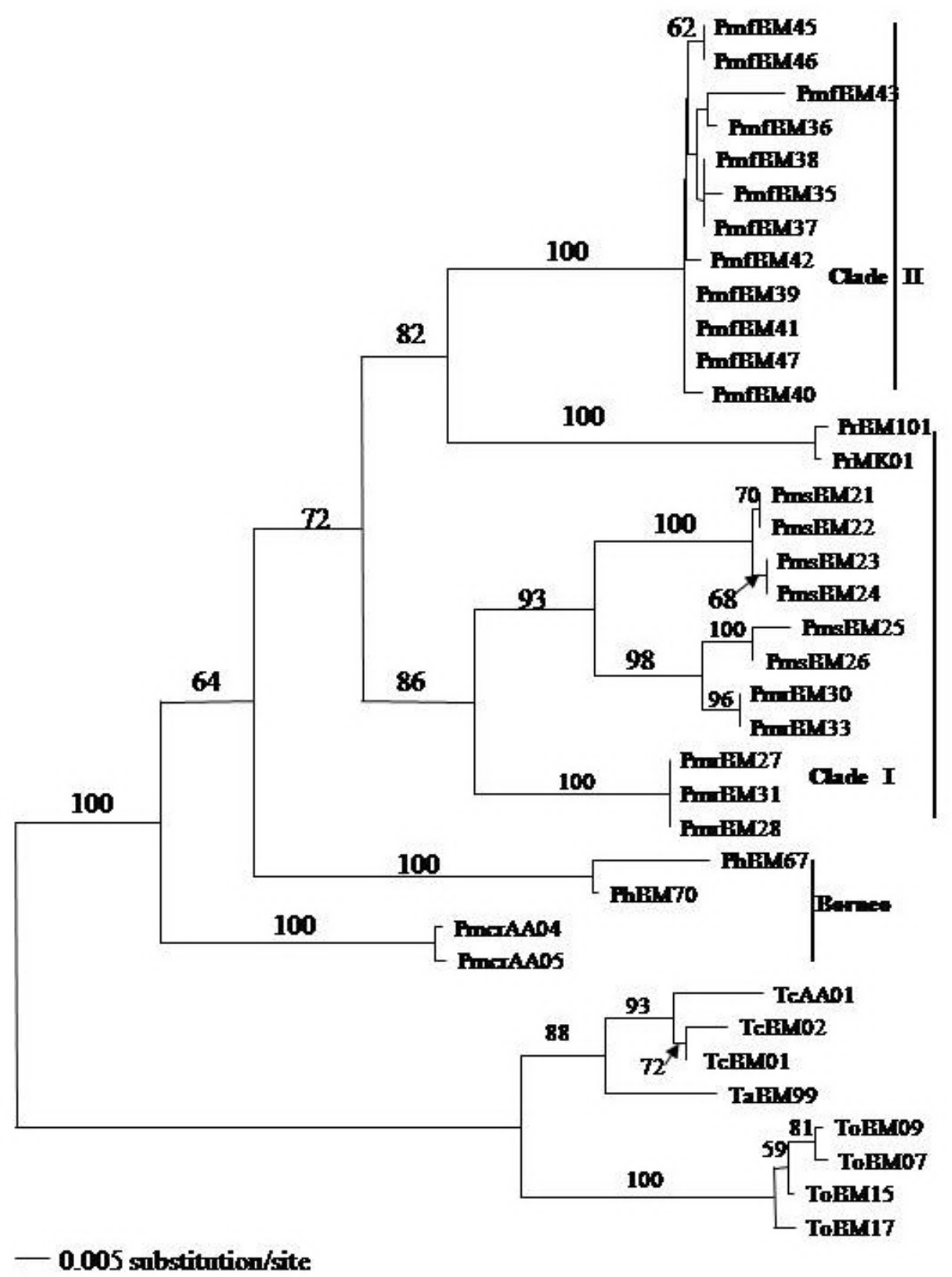

Figure 2. Neighbor joining phylogram of Cyt $b$ based on the Kimura-2-parameter. Number above branches is the bootstrap value (1000 replications). 


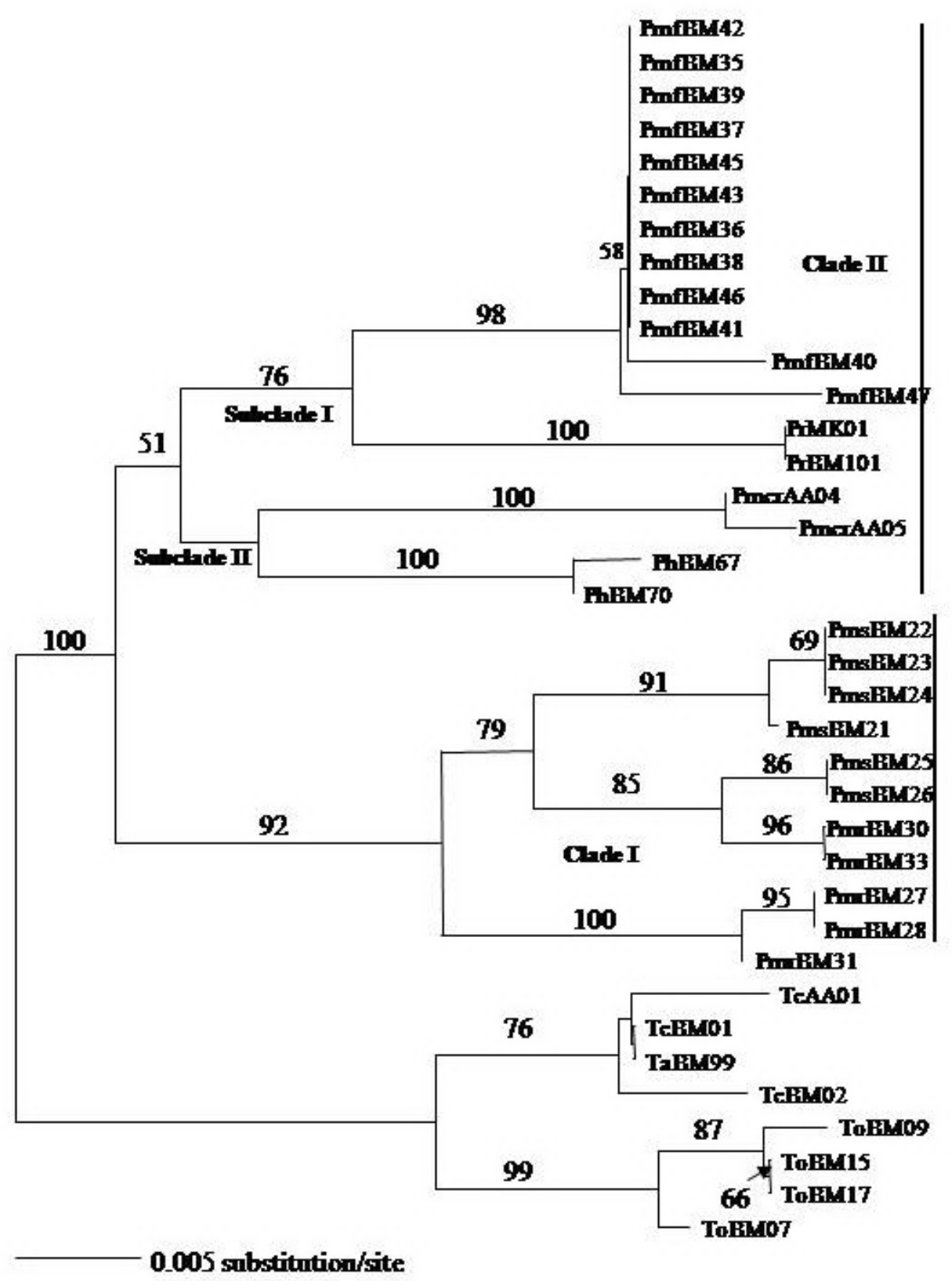

Figure 3. Neighbor joining phylogram of $12 \mathrm{~S}$ rRNA based on the Kimura-2-parameter. Number above branches is the bootstrap value (1000 replications). 


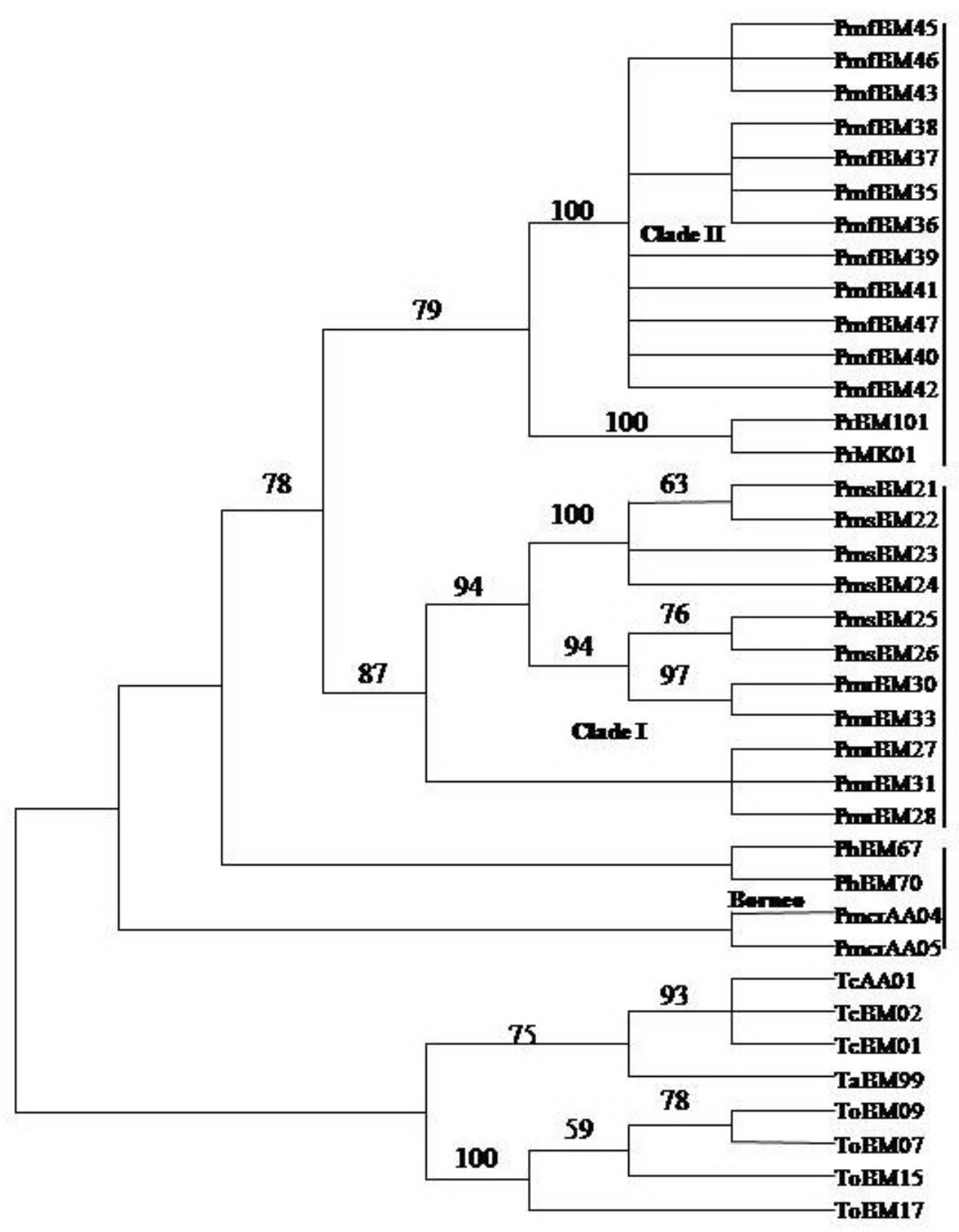

Figure 4. The maximum parsimony heuristic bootstrap tree of Cyt $b$. The bootstrap support values are shown above the branches of the parsimony tree. 


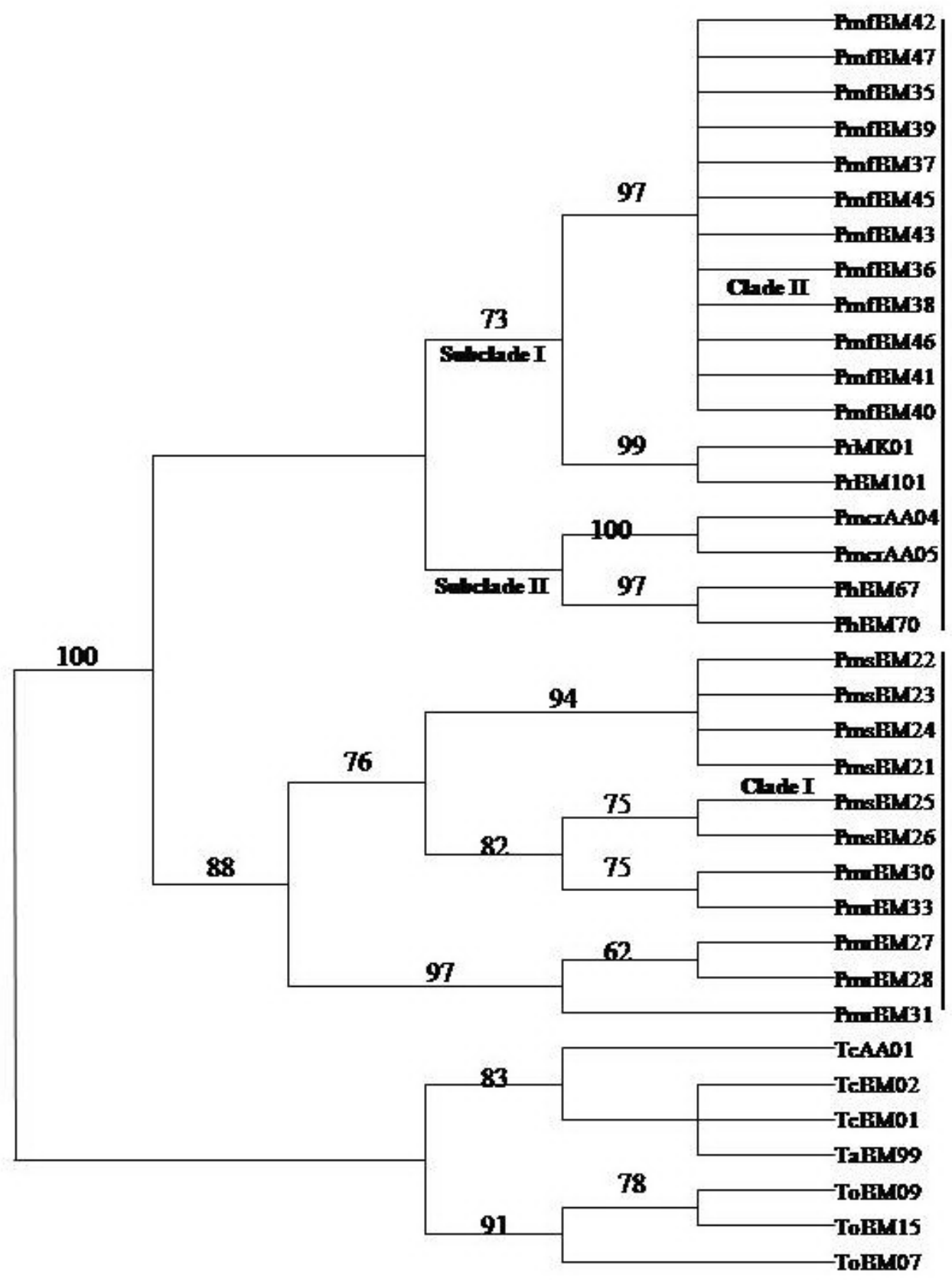

Figure 5. The maximum parsimony heuristic bootstrap tree of $12 \mathrm{~S}$ rRNA. The bootstrap support values are shown above the branches of the parsimony tree. 
Interestingly, both the NJ and MP tree topologies for both the Cyt $b$ and 12S rRNA genes also revealed the clustering of Borneo P. rubicunda with $P$. m. femoralis of Peninsular Malaysia (Clade II), with high bootstrap values (Cyt $b$ : NJ $=82$ and $\mathrm{MP}=79,12 \mathrm{~S}$ rRNA: NJ $=76$ and $\mathrm{MP}=73$ ). Based on the Cyt $b \mathrm{NJ}$ and MP trees, the Borneo endemic $P$. hose $i$ and P. $m$. chrysomelas were found to be more primitive than those of Peninsular Malaysia, with P. $m$. chrysomelas as the most basal to the other Presbytis. Our 12S rRNA NJ and MP trees, however, did not give similar results as for Cyt $b$ due to poor bootstrap value. The 12S rRNA tree topologies only showed a close relationship of the chrysomelas-hosei (subclade II) with rubicunda-melalophos (subclade II).

In order to obtain more DNA information about the chrysomelas individuals, that had previously not been included in any molecular study (Md-Zain et al., 2008) and thought to be a subspecies of melalophos, a close examination of the nucleotide sequences of the chrysomelas was conducted and surprisingly, Cyt $b$ and 12S RNAs both showed a high number of mutations in these individuals. As many as 19 point mutations were found in the Cyt $b$ nucleotide sequence of the two chrysomelas. These point mutations were not found in any of the melalophos. Meanwhile, comparison of chrysomelas $12 \mathrm{~S}$ rRNA nucleotide sequences with all the melalophos showed that one of the chrysomelas (AA05) had a very large number of point mutations (39.4\%). However, the causes of the high mutation rate in chrysomelas individuals could not be ascertained.

\section{DISCUSSION}

The results of the present study of partial Cyt $b$ and $12 \mathrm{~S}$ rRNA genes provide evidence to clarify the classification of Presbytis and the relationships among taxa in Presbytis. Based on the morphological data, it was found that Presbytis generally had the most variable fur coloration across the taxa, thus complicating the recognition task. Classification based solely on morphological traits could not give conclusive results, as the morphological traits were derived or influenced by the environment surrounding the particular animal.

Traditionally, a subspecies is said to be of the same species when they share the same geographical location or habitat, same morphological and behavioral charateristics, and evolutionary history, especially if capable of interbreeding within the same taxa (O'Brian and Mayr, 1991). Based on the morphological, ecological and behavioral data, Oates et al. (1994) suggested that $P$. chrysomelas be classified as a subspecies of the Borneo P. melalophos. However, Brandon-Jones et al. (2004) and Groves $(2001,2005)$ disagreed with this suggestion. Instead of clustering the chrysomelas into any existing taxa, Groves $(2001,2005)$ awarded this primate species status, including under it another subspecies, namely $P$. c. cruciger. Thus, the chrysomelas became a two subspecies taxon. Meanwhile, Brandon-Jones et al. (2004) classified the chrysomelas as a subspecies of femoralis. Our analysis of the partial Cyt $b$ and $12 \mathrm{~S}$ rRNA gene sequences revealed extra-specific point mutations occurring within the nucleotide sequences of chrysomelas, which were not found in any of the melalophos. Therefore, our findings on the classification closely resemble those of Groves (2001, 2005). However, it is still too early to conclude that the chrysomelas is a distinct species due to unavoidable factors, such as only two representative samples of $P$. m. chrysomelas and the lack of cruciger in this study.

Our data, however, did not concur with Presbytis divergence as proposed by BrandonJones (1996a). He hypothesized that the divergence of Presbytis originated from Mentawai Island of Sumatra, Indonesia, which was solely based on the coat coloration of the animal. 
Based on the molecular evolution of the Cyt $b$ gene, chrysomelas was found to have the earliest divergence, which is in accordance with the findings of Peng et al. (1993), indicating that two major evolution events may have happened in the history of Colobinae. The first was centered around the geographical area of Heng Duan, China, whereas the second was centered in the Sundaland including Borneo, Peninsular Malaysia, Sumatra and Java, Indonesia. The latter was supported by molecular data (Md-Zain, 2001). Based on molecular data, Md-Zain (2001) hypothesized that the divergence originated in Borneo, and later moved towards Peninsular Malaysia and Sumatra. The divergence was further complicated by the fact that Borneo remained as part of Asian mainland (linked to the Asian mainland through Peninsular Malaysia and Sumatra) before the Miocene or Pliocene (Wilson and Moss, 1999; Hall, 2001). The paleographical data obtained also showed that the migration of life forms on the Asian mainland and Sundaland was enabled through land bridges during the Pleistocene period (Sartono, 1973; Heaney, 1986; Tjia, 1996). Therefore, the cladogenic activity in Borneo made it possible for the primates to migrate to Sumatra and Java, Indonesia and Peninsular Malaysia through the land bridges connecting them.

The P. melalophos taxa (femoralis, siamensis and robinsoni) were clustered in two different clades, with one consisting of $P$. $m$. siamensis and $P$. $m$. robinsoni, while $P$. $m$. femoralis clustered together with $P$. rubicunda, which is in contrast with the findings of Md-Zain (2001). However, the observation by Brandon-Jones (1977) based on coat coloration provides useful information to explain the current findings. The most primitive color, as suggested by BrandonJones (1977), would be the dark color, followed by the intermediate color and lastly the derived color, which has the most variable color, ranging from brown to maroon. According to him, both melalophos and rubicunda are of the same category of coat color, that is the derived color. Brandon-Jones (1996b) further suggested a special affinity of $P$. melalophos with $P$. rubicunda based on the behavioral similarity between the two species. Thus, our findings on the clustering of $P$. melalophos and P. rubicunda were well supported by both morphological and behavioral data.

P. $m$. siamensis and P. $m$. robinsoni, as shown in the NJ and MP tree topology, were not clustered together with P. m. femoralis. According to Aimi and Bakar (1992), P. melalophos is a sister species to P. femoralis ( $P$. m. femoralis in the present study) and $P$. thomasi (not included in the present study). The field observation carried out by the authors in Sumatra showed significant differences with regard to the morphological aspect as well as geographical area. Based on these observations, both femoralis and melalophos were recognized as distinct species. However, their study did not include any primate individual available in Malaysia. Bennett and Bennett (1988), who worked on the Malaysian primates, found that the vocalization of $P$. femoralis and P. melalophos were not as consistent as observed by Aimi and Bakar (1992), and proposed that both the species are actually conspecific, which means they are of the same species but highly variable. The separation of femoralis from melalophos was also supported by Wilson and Wilson (1977) based on both the coat color and vocalization of adult individuals.

Brandon-Jones et al. (2004) classified P. femoralis and P. siamensis as distinctive species that consist of six subspecies and five subspecies, respectively. According to authors, robinsoni, chrysomelas and femoralis are subspecies of femoralis. Our constructed Cyt $b$ tree topology, however, did not meet such classification. Instead, our analysis showed a classification closer to that of Oates et al. (1994) and Md-Zain (2001). Meanwhile, chrysomelas showed a specific affinity that follow Groves $(2001,2005)$ but not Brandon-Jones et al. (2004). Thus, its status remains unclear. The efforts to clarify the current status of Presbytis were further 
complicated by the difficulties to obtain specimens for the complete species list of the genus. Even though there is still some doubt, the present study has generally provided us with a clearer picture of Prebytis classification. Further studies should incorporate more species samples and more loci and relationships with other Asian leaf monkeys as previously described in Trachypithecus and Semnopihecus and odd noses (Karanth et al., 2008; Osterholz et al., 2008; Roos et al., 2008; Ting et al., 2008; Md-Zain et al., 2008, 2010b).

\section{ACKNOWLEDGMENTS}

We are deeply indebted to Dr. Nordin Hassan, Dr. Don J. Melnick, Dr. Jasmi Abdul, Mr. Hatta Ramlee and several institutions that provided us with the necessary facilities and assistance for tissue sample collection, including the Faculty of Science and Technology, Universiti Kebangsaan Malaysia, Department of Wildlife and National Parks, Zoo Taiping, Zoo Melaka, Singapore Zoological Gardens, Sarawak Forestry Department, Centre of Biological Diversity Sarawak and Sabah Parks, Malaysia. We thank Dr. S.O. Kolokotronis from the American Museum of Natural History for helpful discussions and advice. The authors also wish to thank the reviewers of this paper for their help in refining the manuscript. This research was made possible under grants UKM-ST-08-FRGS0012-2010, UKM J/1/98, UKM-OUP-PLW-10-43/2010, UKM-OUP-FST-2010, UKM-OUP-TKP-20-98/2010, and IRPA 0802020019 EA301.

\section{REFERENCES}

Aimi M and Bakar A (1992). Taxonomy and Distribution of Presbytis melalophos Group in Sumatera. Primates, Indonesia, 191-206.

Ampeng A and Md-Zain BM (2007). A Short Note on Methodology of Detecting Leaf Monkeys (Presbytis melalophos chrysomelas and Trachypithecus crisatus) in Samunsam Wildlife Sanctuary, Sarawak. The Journal of Wildlife and Parks 24: 7-9.

Bennett EL and Bennett JM (1988). A Survey of Primates in Ulu Sebuyan. Report to Sarawak Forest Department, Kuching, Sarawak, Malaysia.

Brandon-Jones D (1977). The Evolution of Recent Asian Colobines. In: Recent Advances in Primatology (Chivers DJ and Joysey KA, eds.). Academic Press, London, 323-325.

Brandon-Jones D (1996a). The Asian Colobinae (Mammalia: Cercopithecidae) as indicators of quaternary climatic change. Biol. J. Linnean Soc. 59: 327-350.

Brandon-Jones D (1996b). Presbytis Species in Sympatry in Borneo Versus Allopatry in Sumatra: An Interpretation. In: Tropical Rainforest Research - Current Issues (Edwards DSEA, ed.). Kluwer Academic Publishers, Netherlands, 71-76.

Brandon-Jones D, Eudey AA, Geissmann T, Groves CP, et al. (2004). Asian primate classification. Int. J. Primatol. 25: 97-164.

Groves CP (2001). Primate Taxonomy. Smithsonian Institution Press, Washington.

Groves CP (2005). Order Primates. In: Mammal Species of the World. The Johns Hopkins University Press, Baltimore, 111-184.

Hall R (2001). Cenozoic Reconstructions of SE Asia and the SW Pacific: Changing Pattern of Land and Sea. In: Fauna and Flora Migrations and Evolutions in SE Asia-Australasia (Metcalfe I, ed.). Swets and Zeitlinger Publisher, Balkema Lisse, 35-56.

Heaney LR (1986). Biogeography of mammals in SE Asia: estimates of rates of colonization, extinction and speciation. Bio. J. Linn. Soc. 28: 127-165.

Karanth KP (2008). Primate numts and reticulate evolution of capped and golden leaf monkeys (Primates: Colobinae). $J$. Biosci. 33: 761-770.

Karanth KP, Singh L, Collura RV and Stewart CB (2008). Molecular phylogeny and biogeography of langurs and leaf monkeys of South Asia (Primates: Colobinae). Mol. Phylogenet. Evol. 46: 683-694. 
Khan HA, Arif IA, Al Homaidan AA and Al Farhan AH (2008). Application of 16S rRNA, cytochrome b and control region sequences for understanding the phylogenetic relationships in Oryx species. Genet. Mol. Res. 7: 1392-1397.

Kimura M (1980). A simple method for estimating evolutionary rates of base substitutions through comparative studies of nucleotide sequences. J. Mol. Evol. 16: 111-120.

Kocher TD, Thomas WK, Meyer A, Edwards SV, et al. (1989). Dynamics of mitochondrial DNA evolution in animals: amplification and sequencing with conserved primers. Proc. Natl. Acad. Sci. U. S. A. 86: 6196-6200.

Kumar S, Tamura K and Nei M (2004). MEGA3: integrated software for molecular evolutionary genetics analysis and sequence alignment. Brief. Bioinform. 5: 150-163.

Lim LS, Ang KC, Mahani MC, Shahrom AW, et al. (2010). Mitochondrial DNA polymorphism and phylogenetic relationships of Proto Malays in Peninsular Malaysia. J. Biol. Sci. 10: 71-83.

Md-Zain BM (2001). Molecular Systematics of the Genus Presbytis. Doctoral dissertation, Columbia University, New York.

Md-Zain BM, Morales JC, Hassan MN, Jasmi A, et al. (2008). Is Presbytis a distinct monophyletic genus: inferences from mitochondrial DNA sequences. Asian Primates J. 1: 26-36.

Md-Zain BM, Lee SJ, Lakim M, Ampeng A, et al. (2010a). Phylogenetic position of Tarsius bancanus based on partial cytochrome b DNA sequences. J. Biol. Sci. 10: 348-354.

Md-Zain BM, Mohamad M, Ernie-Muneerah MA, Ampeng A, et al. (2010b). Phylogenetic relationships of Malaysian monkeys, Cercopithecidae, based on mitochondrial cytochrome c sequences. Genet. Mol. Res. 9: 1987-1996.

Medway L (1970). The Monkeys of Sundaland: Ecology and Systematics of the Cercopithecids of a Humid Equatorial Environment. In: Old World Monkeys: Evolution, Systematics and Behavior (Napier JR and Napier PH, eds.). Academic Press, New York, 513-553.

Meijaard E and Groves CP (2004). The biogeograpical evolution and phylogeny of the genus Presbytis. Primate Rep. 68: 90.

Melnick DJ and Hoelzer GA (1993). What is mtDNA good for in the study of primate evolution? Evol. Anthropol. 2: 2-10.

Napier PH (1985). Catalogue of Primates in the British Museum (Natural History) and Elsewhere in the British Isles III. Family Cercopithecidae, Subfamily Colobinae. British Museum (Natural History), London.

O'Brian SJ and Mayr E (1991). Bureaucratic mischief: recognizing endangered species and subspecies. Science 251: 1187-1188.

Oates JF, Davies AG and Delson E (1994). The Diversity of Living Colobines. In: Colobine Monkey: Their Ecology, Behavior and Evolution (Davies AG and Oates JF, eds.). Cambridge University Press, Cambridge, 45-73.

Osterholz M, Walter L and Roos C (2008). Phylogenetic position of the langur genera Semnopithecus and Trachypithecus among Asian Colobines, and genus affiliations of their species groups. BMC Evol. Biol. 8: 58.

Pääbo S and Wilson AC (1988). Polymerase chain reaction reveals cloning artefacts. Nature 334: 387-388.

Peng YZ, Pan RL and Jablonski NG (1993). Classification and evolution of Asian Colobines. Folia Primatol. 60: 106-117.

Roos C, Nadler T and Walter L (2008). Mitochondrial phylogeny, taxonomy and biogeography of the silvered langur species group (Trachypithecus cristatus). Mol. Phylogenet. Evol. 47: 629-636.

Sartono S (1973). On the Pleistocene migration routes of vertebrate fauna in Southeast Asia. Geol. Soc. Malaysia 6: 273286.

Shahrom AW, Lim LS, Md-Zain BM, Mahani MC, et al. (2005). 2-D facial reconstruction (when skull is not available) using mitochondrial DNA (mtDNA) phylogeny tree and image morphing techniques: a preliminary study. Int. J. Med. Toxicol. Legal Med. 8: 1-5.

Sterner KN, Raaum RL, Zhang YP, Stewart CB, et al. (2006). Mitochondrial data support an odd-nosed Colobine clade. Mol. Phylogenet. Evol. 40: 1-7.

Swofford DL (2002). Phylogenetic Analysis Using Parsimony and other Methods. Version 4.0. Beta Version. Sinauer Associates, Sunderland.

Thompson JD, Gibson TJ, Plewniak F, Jeanmougin F, et al. (1997). The CLUSTAL_X windows interface: flexible strategies for multiple sequence alignment aided by quality analysis tools. Nucleic Acids Res. 25: 4876-4882.

Ting N, Tosi AJ, Li Y, Zhang YP, et al. (2008). Phylogenetic incongruence between nuclear and mitochondrial markers in the Asian Colobines and the evolution of the langurs and leaf monkeys. Mol. Phylogenet. Evol. 46: 466-474.

Tjia HD (1996). Sea-level changes in the tectonically stable Malay-Thai Peninsula. Quat. Int. 31: 101.

Wilson CC and Wilson WL (1977). Behavioral and morphological variations among primate population in Sumatra. Yearbook Phys. Anthropol. 20: 207-233.

Wilson MEJ and Moss SJ (1999). Cenozoic palaeographic evolution of Sulawesi and Borneo. Palaeogeogr. Palaeoclimatol. Palaeoecol. 145: 303-337. 